\title{
Effects of kinship, age, and sex on social preferences in rats measured in an operant response situation
}

\author{
RICHARD DENI, JOSEPH VOCINO, and MICHAEL EPSTEIN \\ Rider College, Lawrenceville, New Jersey 08648
}

\begin{abstract}
Latane and his co-workers have reported that several static stimulus variables do not affect social attraction between laboratory rats tested in an open-field apparatus. These variables include absence of fur, color of fur, perfumed fur, and sex of subject. Experiments are reported here that suggest that static stimulus variables related to kinship, age, and sex of companion exert a significant influence on social attraction and social exploration measured in an operant response situation. Social operant behavior varied as a function of stimulus factors in several situations: littermates paired with other littermates vs. strangers, dams exposed to young offspring vs. young strangers, dams exposed to young offspring vs. adult offspring, and adult rats exposed to their dams or to strange females.
\end{abstract}

One of the positions taken by Latané and his co-workers concerning the control of social attraction in rats has been to discount the role of static stimulus characteristics. Latané, Joy, Meltzer, Lubell, and Cappell (1972) ruled out several factors that did not affect social attraction when compared with a normal intact albino rat as a companion. These factors included fur dyed with black ink, fur completely shaven, and fur sprayed with perfume. Further research by Latané, Edwards, Steele, and Walton (1973) has ruled out the physical differences associated with cross-strain pairings of rats during the social attraction test in the open field. There was no difference in social attraction scores when cross-strain pairs were compared with same-strain pairs. Similar findings were reported for same-sex pairs compared with opposite-sex pairs of rats (Sloan \& Latané, 1974).

The experiments reported here provide a further test of the role of static stimulus variables in the control of social attraction in rats. Social attraction was operationally defined here as an operant response that gained sensory access to a companion in an enclosure adjacent to the subject. Experiment 1 was a replication of the basic test situation used by Walton and Latane (1972) comparing social attraction of rats housed alone with rats housed in pairs. Experiments 2, 3, 4, and 5 evaluated the effects of several static stimulus variables. Experiment 2 tested adult male rats in the presence of either male or female littermates or strangers. Experiment 3 tested adult primiparous females in the presence of either one male or a group of six male weanling offspring or strangers. Experiment 4 tested adult multi-

Address reprint requests to Richard Deni, Psychology Department, Rider College, Lawrenceville, New Jersey 08648. parous females in the presence of their own juvenile or adult offspring or strangers. Experiment 5 tested adult male and female subjects in the presence of their dams or a strange adult female.

\section{GENERAL METHOD}

The apparatus used in all the experiments consisted of a modified rodent operant chamber enclosed in a soundattenuating cabinet. The manipulanda, cue lights, and food cup were removed from the metal front panel, and a small $4-\mathrm{cm}$ porthole was installed centered $20 \mathrm{~cm}$ above the floor of the chamber. All other openings in the front metal panel were covered. A small metal ramp was located inside the chamber leading from the floor up to the porthole. When a rat inside the chamber poked its head through the hole, it gained sensory access to a small adjoining compartment in which stimulus animals could be located. This companion compartment measured $15 \times 20 \times 20 \mathrm{~cm}$ and was constructed with Plexiglas walls and a wire-mesh cover. A photocell beam was projected across the porthole opening. When the beam was broken by a peeking response, the companion compartment was illuminated and a running timer recorded the duration of peeks (social operant responses) to the nearest $.1 \mathrm{sec}$.

\section{EXPERIMENT 1: ADULT MALE RATS WITH FAMILIAR AND UNFAMILIAR COMPANIONS}

\section{Method}

Subjects. Subjects were 14 adult male Long-Evans rats. These animals were also used as familiar companions. Unfamiliar companions were seven adult male Long-Evans rats.

Procedure. Subjects were housed in pairs from 50 days of age until testing began at 100 days of age. Unfamiliar companions were housed individually. On Day 1 subjects were placed inside the operant chamber for a single 15 -min adaptation session with an empty companion compartment and an inoperative photocell unit. On Days 2, 3, and 4, subjects were tested during daily 15 -min sessions in the chamber under three conditions in a withinsubjects design: empty companion compartment, familiar cagemate present, and unfamiliar rat present. The order of conditions was randomized for each subject. The choice of unfamiliar companion was also determined at random. 
Table 1

Means and Standard Deviations for Duration (in seconds) of Social Operant Responding per 15-Min Session by Adult Males as a Function of Companion Condition

\begin{tabular}{ccc}
\hline \multicolumn{1}{c}{ Condition } & Mean & SD \\
\hline Empty Compartment & 36.9 & 15.9 \\
Familiar Companion* & 55.3 & 18.5 \\
Unfamiliar Companion & 58.2 & 21.5 \\
\hline
\end{tabular}

*Cagemate.

\section{Results and Discussion}

The average duration of social operant responses for each companion condition is reported in Table 1. Differences in the duration of operant responding as a function of companion condition were significant $[\mathrm{F}(2,26)=$ $12.07, \mathrm{p}<.05$ ]. Tukey's test showed that both familiar and unfamiliar companion conditions were preferred over no companion $(\mathrm{p}<.05)$.

The operant behavior reported here parallels the stable finding of earlier research in which rats were tested in the open field with percentage of time in contact as the measure of social attraction (Walton \& Latané, 1972). Walton and Latané reported that grouphoused pairs spent less time in contact compared with isolate-housed rats.

\section{EXPERIMENT 2: ADULT MALE RATS WITH MALE AND FEMALE LITTERMATES AND STRANGERS AS COMPANIONS}

\section{Method}

Subjects. Subjects were seven adult male Long-Evans rats, each originating from a separate litter. Littermate companions were seven adult male Long-Evans rats and seven adult female Long-Evans rats. Each male and female littermate was obtained from the same litter as a given subject. Unfamiliar companions were seven adult male and seven adult female Long-Evans rats not obtained from subject litters. All rats were housed individually from 40 days of age until testing at 100 days of age.

Procedure. On Day 1 subjects were adapted to the operant chamber using the procedure described in Experiment 1 . Over the next 4 days, subjects were tested during daily 15 -min sessions in the chamber under the four conditions of a 2 by 2 within-subjects design: male or female littermate present, and male or female stranger present in the companion compartment. The order of conditions was randomized for each subject.

\section{Results and Discussion}

The average duration of social operant behavior for each companion condition is reported in Table 2 . Differences in the duration of operant responding as a function of companion sex were significant $[F(1,6)=$ $8.78, \mathrm{p}<.05]$. Differences in responding as a function of littermate vs. stranger were also significant $[F(1,6)=$ $14.03, \mathrm{p}<.05]$. No significant interaction was obtained. Overall, the duration of social operant responding was greater in the presence of a female companion compared with a male and greater in the presence of a littermate compared with a stranger.

\section{EXPERIMENT 3: ADULT DAMS WITH ONE MALE VS. SIX MALE WEANLING OFFSPRING OR STRANGERS}

\section{Method}

Subjects. Subjects were eight adult primiparous female Long-Evans rats having had litters containing a minimum of six male pups. Each subject originated from a separate litter. Offspring companions were chosen from among each subject's own litter. Unfamiliar companions were chosen from among the other subject litters. Pups were 20 days old at the start of the procedure and were housed with the dam in standard plastic cages.

Procedure. On Day 1 subjects were adapted to the operant chamber using the same procedure used in the previous experiments. Over the next 4 days, subjects were tested during daily 15 -min sessions in the chamber under the four conditions of a 2 by 2 within-subjects design: one or six male offspring or strangers present in the companion compartment. The order of conditions was randomized for each subject. The choice of specific male offspring or male strangers as companions was also determined at random for each session.

\section{Results and Discussion}

The average duration of social operant behavior for each companion condition is reported in Table 3. Analysis of variance indicated a significant interaction of the offspring-stranger factor with number of companions present $[F(1,7)=16.51, p<.05]$. Tukey's test showed one specific comparison to be significant $(p<.05)$. Response duration was significantly greater when a single male weanling stranger was present compared with a single male offspring. According to this measure of social attraction, dams are more interested in gaining access to unfamiliar weanling pups compared with pups from their own litter.

Table 2

Overall Means and Standard Deviations for Duration (in seconds) of Social Operant Responding per 15-Min Session by Adult Males as a Function of Companion Condition

\begin{tabular}{lrr}
\hline \multicolumn{1}{c}{ Condition } & Mean & SD \\
\hline Male Companion & 74.7 & 37.8 \\
Female Companion & 97.6 & 40.6 \\
\hline Littermate Companion & 100.3 & 37.4 \\
Unfamiliar Companion & 71.9 & 39.2 \\
\hline
\end{tabular}

Table 3

Means and Standard Deviations for Duration (in seconds) of Social Operant Responding per 15-Min Session by Primiparous Females as a Function of Companion Condition

\begin{tabular}{lcc}
\hline \multicolumn{1}{c}{ Condition } & Mean & SD \\
\hline Offspring/Single Male & 26.7 & 9.8 \\
Offspring/Six Males & 47.3 & 15.1 \\
Unfamiliar/Single Male & 57.9 & 24.6 \\
Unfamiliar/Six Males & 40.4 & 27.8 \\
\hline
\end{tabular}




\section{EXPERIMENT 4: ADULT DAMS WITH A SINGLE ADULT MALE OR JUVENILE MALE OFFSPRING OR STRANGER}

\section{Method}

Subjects. Subjects were five adult multiparous female LongEvans rats originally obtained from separate litters. Adult offspring companions were chosen from among a group of male first-generation offspring approximately 100 days old at the start of the study. Juvenile offspring companions were chosen from among a group of male second-generation offspring approximately 40 days old at the start of the study. All companions were separated from their dams at 21 days of age and were housed individually from 30 days of age. Unfamiliar companions were chosen from among adults and juveniles from litters other than subject litters.

Procedure. On Day 1 subjects were adapted to the chamber using the standard procedure. Over the next 4 days, subjects were tested during daily $15-\mathrm{min}$ sessions in the chamber under the four conditions of a 2 by 2 within-subjects design: adult male or juvenile male offspring or stranger present in the companion compartment. The order of conditions and the choice of specific offspring and strangers were randomized for each subject.

\section{Results and Discussion}

Table 4 shows the average duration of social operant behavior for each companion condition. Analysis of variance indicated a significant interaction of the offspring-stranger factor with age of companion $[F(1,4)=12.31, p<.05]$. An adult male stranger was the most attractive social stimulus, which may be related to sexual attraction. However, Sloan and Latané (1974) have reported that rats in the open field show equivalent social attraction to opposite-sex companions compared with same-sex companions.

\section{EXPERIMENT 5: ADULT MALES AND FEMALES WITH THEIR DAM OR UNFAMILIAR FEMALE PRESENT}

\section{Method}

Subjects. Subjects were seven adult male Long-Evans rats and seven adult female Long-Evans rats originally obtained from separate litters. The companions consisted of either the subject's dam or an unfamiliar adult female.

Procedure. Subjects were adapted to the apparatus on Day 1. Over the next 3 days, the two groups of subjects were tested during daily 15 -min sessions under three within-subjects conditions: empty compartment, dam present, unfamiliar female present. The order of within-subjects conditions was randomly determined for each subject.

\section{Results and Discussion}

Table 5 shows the mean duration of social operant behavior for the male and female subjects under each companion condition. Analysis of variance indicated that differences in responding as a function of companion conditions were significant $[F(2,24)=8.31$, $\mathrm{p}<.05]$. Overall, these rats showed the greatest social
Table 4

Means and Standard Deviations for Duration (in seconds) of Social Operant Responding per 15-min Session by Multiparous Females as a Function of Companion Condition

\begin{tabular}{lrl}
\hline \multicolumn{1}{c}{ Condition } & Mean & SD \\
\hline Adult Male/Offspring & 71.4 & 16.4 \\
Adult Male/Unfamiliar & 115.9 & 66.7 \\
Juvenile Male/Offspring & 109.7 & 46.7 \\
Juvenile Male/Unfamiliar & 83.0 & 50.6 \\
\hline
\end{tabular}

Table 5

Overall Means and Standard Deviations for the Duration (in seconds) of Social Operant Responding per 15-Min Session by Adult Males and Females as a Function of Companion Condition

\begin{tabular}{lcc}
\hline \multicolumn{1}{c}{ Condition } & Mean & SD \\
\hline Empty Compartment & 20.2 & 26.7 \\
Dam Present & 34.3 & 40.9 \\
Unfamiliar Female & 50.2 & 61.8 \\
\hline
\end{tabular}

attraction to an unfamiliar female, suggesting that the subjects discriminated between the dam and the unfamiliar female.

\section{GENERAL DISCUSSION}

Previous research using measures of social contact in the open field ruled out several different static factors as having little influence on social attraction (Latané, et al., 1973; Latané, Joy, Meltzer, Lubell, \& Cappell, 1972; Latané, Nesbitt, Eckman, \& Rodin, 1972; Sloan \& Latané, 1974). One static stimulus factor that does seem to have an effect in open-field measures of attraction is species difference. Hall and Latane (1975) reported that rats spend significantly more time in contact with another rat than with a gerbil.

The experiments reported here have demonstrated that static stimulus factors will influence social attraction as defined by present operant procedures. The data reported here suggest that kinship, sex, and age differences can form the basis for social discriminations and differential social attraction in rats.

\section{REFERENCES}

Hall, D., \& Latané, B. Acceptance and preference for same and cross-species contact in rats. Bulletin of the Psychonomic Society, 1975, 3, 245-247.

Latané, B., Edwards, J., Steele, C., \& Walton, D. Social attraction among and between albino and hooded rats. Bulletin of the Psychonomic Society, 1973, 2, 20-22.

Latané, B., Joy, V., Meltzer, J., Lubell, B., \& Cappell, H. Stimulus determinants of social attraction in rats. Journal of Comparative and Physiological Psychology, 1972, 79, 13-21.

Latané, B., Nesbitt, P., Eckman, J., \& Rodin, J. Long- and short-term social deprivation and sociability in rats. Journal of Comparative and Physiological Psychology, 1972, 81, 69-75.

Sloan, L., \& Latané, B. Sex and sociability in rats. Journal of Experimental Social Psychology, 1974, 10, 147-158.

Walton, D., \& LAtané, B. Visual vs. physical social deprivation and affiliation in rats. Psychonomic Science, 1972, 26, 4-6.

(Received for publication April 30, 1980.) 